\title{
CT Scan Pattern of Stroke Patients at Jimma University Medical Center, South West Ethiopia
}

\author{
Abdi Dandena ${ }^{1 *}$, Melese sinaga ${ }^{2}$, Yeneneh Yirga ${ }^{3}$ and Tadege Zelalem ${ }^{4 *}$ \\ ${ }^{1}$ Department of Radiology, Faculty of Medical Science, Institute of Health, Jimma University, Ethiopia \\ ${ }^{2}$ Nutritional Unit, Department of Population and Family Health, Faculty of Public Health, Institute of Health, Jimma \\ University, Ethiopia \\ ${ }^{3}$ Department of Surgery, Faculty of Medical Science, Institute of Health, Jimma University, Ethiopia \\ ${ }^{4}$ Department of Radiology, Faculty of Medical Science, Institute of Health, Jimma University, Ethiopia \\ *Corresponding author: Abdi Dandena, Department of Radiology, Faculty of Medical Science, Institute of Health, Jimma \\ University, Ethiopia
}

\section{ARTICLE INFO}

Received: 嵊 August 11, 2020

Published: August 20, 2020

Citation: Abdi Dandena, Melese sinaga, Yeneneh Yirga and Tadege Zelalem. CT Scan Pattern of Stroke Patients at Jimma University Medical Center, South West Ethiopia. Biomed J Sci \& Tech Res 29(4)2020. BJSTR. MS.ID.004835.

Keywords: Computerized Tomography; Hemorrhage; Infarction; Ethiopia; Stroke

Abbreviations: CT: Computed Tomography; ICH: Intra-Cerebral Hemorrhage; JUMC: Jimma University Medical center; LMIC: low- and middle-income countries; SAH: Sub- Arachnoid Hemorrhage; SPSS: Statistical Software for Social Sciences

\section{ABSTRACT}

Background: Stroke is becoming a significant cause of morbidity and mortality in low and middle-income countries. And accurate diagnosis and management of stroke relies on Neuroimaging.

Objective: To determine the CT scan pattern, as well as associated risk factors of stroke patients attending Jimma University Medical Center

Methods: A hospital-based retrospective study was conducted on all patients with a CT scan of the head with the diagnosis of stroke at JUMC from December 11, 2016, up to October 8, 2019, southwest Ethiopia. Data was analyzed using SPSS V 24 Software. And the results were presented using tables and Figures.

Results: A total of 536 patients have undergone head CT for a clinical diagnosis of stroke during the study period and from those 250 people were included in the study, $184(65 \%)$ were male and $99(35 \%)$ were female. And 180(63.9\%) were from rural areas while the rest $103(36.4 \%)$ of came from urban regions. The mean age was $(57 \pm 14$ years. The most common pattern of stroke in the CT findings was hemorrhagic stroke with $126(44.5 \%)$ followed by ischemic stroke $122(43.1 \%)$.

Conclusion: The study shows that stroke is a major public health concern and A prospective community-based study is required to define the true magnitude and socio-demographic characteristics of stroke and the associated factors in the general population. Strategies for screening and management of hypertension, structural heart disease, and atrial fibrillation should be given priority as these are the most prevalent risk factors identified.

\section{Introduction}

Cardiovascular disease is the primary global cause of death, responsible for more than 17.3 million deaths annually, and according to data gathered from the Global Burden of Diseases (GBD) the number that is projected to exceed 23.6 million by 2030 [1]. Low and middle-income countries are disproportionately affected by the cardiovascular disease as more than $80 \%$ of the death due to cardiovascular disease occurring in low- and middleincome countries (LMICs) according to reports done in 2013 [2]. In sub-Saharan Africa, the incidence of stroke, especially hemorrhagic stroke, may have risen substantially over the last 20 years as have other no communicable diseases. This epidemiologic transition is postulated to be due to a combination of adoption of Western lifestyle, dietary changes, urbanization, and demographic 
transition with increasing life expectancy and population growth [3]. According to the World Health Organization, there were 39,409 stroke deaths in Ethiopia in 2004, which accounted for 3.6\% of all deaths and $15.3 \%$ of deaths from non-communicable diseases [4]. Accurate stroke diagnosis and subtype confirmation plays a big role in patient management and prognosis as Current management protocols depend on clearly differentiating between the subtypes of stroke, Although clinical features cannot reliably distinguish Ischemic Stroke (IS) from Intracerebral Hemorrhage (ICH), several clinical signs increase the likelihood of ICH rather than IS: such as coma, neck stiffness, seizures at onset of neurologic deficit, diastolic blood pressure greater than $110 \mathrm{mmHg}$ vomiting and headache are among the few [5].

Although stroke is becoming a major health problem in lowincome and middle-income countries, there are few available data on stroke in Ethiopia. And there are no available data from the Southwestern part of Ethiopia addressing the demography, risk factors, and burden of stroke. The Jimma University medical center started providing CT scan services since 11/11/2016 with the instalment of a 64 slice GE optima 660 Multi detector CT, before the start of the services clinicians mainly relied on clinical signs and symptoms to diagnose as well as speculate on the subtype of stroke the patients had. And this has hampered the quality of care that can be provided to stroke patients as clinical differentiation of stroke subtypes as well as differentiating stroke from differential diagnosis is unreliable and affects the decision making regarding the type of treatment patients should receive [6]. Therefore, Thus, this study aims to assess the CT scan pattern and associated Risk factors seen in stroke patients coming to JUMC Radiology department with the aim of better understanding the local epidemiology of the Disease and to serve as a benchmark for future researches and interventions regarding the care of stoke patients in the region.

\section{Methods and Materials}

a) Study Area and Period: The study was conducted in the Department of Radiology of JUMC, Jimma, Ethiopia. JUMC is the only referral hospital in the southwestern part of the country providing service for more than 15 million people with a catchment area of 17,000 square km. The Department of Radiology of JUMC is within the Faculty of Medicine of the University and is the only department providing CT scan services in the southwestern part of the country, following its installment back on December 11, 2016. The study was conducted from December 11, 2016, up to October 8, 2019

b) Study Design: A cross-sectional retrospective study design was employed by analyzing data from patient records. Data was collected for the nearly three years' period spanning from December 11, 2016, up to October 8, 2019. c) Source Population: All patients who underwent Head CT at JUMC, Radiology Department between December 11, 2016, up to October 8, 2019.

d) Study Population: Patients who underwent Head CT at JUMC Radiology Department with a clinical diagnosis of Stroke from December 11, 2016, up to October 8, 2019were taken.

e) Sample Size Determination and Sampling Procedure: Convenience non- probability sampling, utilizing inclusion and exclusion criteria was used an record of all patients who underwent head CT for a clinical suspicion of stroke was taken and those patients with incomplete data and with an alternate final diagnosis were excluded from the study.

f) Data Collection and Analysis: Data were collected using a structured data collecting format by general medical practitioners trained in data collection techniques concerning the objective of the study. Data were cleared, edited and analyzed using IBM SPSS v24 software. The presence of an association between the variables was investigated using the Chi-square test. Those with a p-value $<0.05$ were considered to be statistically significant.

\section{Operational Definition}

a) Stroke: It is clinically defined as per WHO criteria, as rapidly developing clinical signs of focal or global disturbance of cerebral function, with symptoms lasting 24 hours or longer or leading to death, with no apparent cause other than the vascular origin [7].

b) Ischemic Stroke: It is evidence of a recent infarct in the clinically relevant area of the brain/confirmed cerebral infarction [2].

c) Hemorrhagic Stroke: It occurs due to the weakening of blood vessel which would rupture and bleed into the surrounding brain tissues [2].

d) Subarachnoid Hemorrhage: This group of strokes is mainly due to the rupture of aneurysms at the bifurcations of large arteries at the inferior surface of the brain [7].

e) Ethical Consideration: A formal letter was written by Jimma University Research and Ethics review board to get ethical clearance and support during data collection. And a letter of approval was provided and data collection commenced with the permission and assistance of the JUMC archive.

\section{Results}

\section{Sociodemographic Characteristics of the Patients}

A total of 536 patients have undergone head CT for a clinical diagnosis of stroke during the study period and from those 283 
people were included in the study, 184(65\%) were male and $99(35 \%)$ were female. And $180(63.9 \%)$ of the patients came from rural areas while the rest $103(36.4 \%)$ of patients came from urban areas (Table 1). The age group most commonly affected by stroke are people above the age of 65 with 95(33.6\%) followed by the age group of 55-64 with 76(26.9\%) and age group 45-54 with $64(22.6 \%)$ and only 11 people below the age of 35 were affected by stroke (Table 1).

Table 1: Socio- demographic characteristics of stroke patients who underwent CT scanning at Jimma University Medical Center.

\begin{tabular}{|c|c|c|c|c|}
\hline \multirow{3}{*}{ Sex } & & Infarction & Hemorrhage & Total \\
\hline & Male & 103 & 81 & 184 \\
\hline \multirow{3}{*}{ Address } & Female & 54 & 45 & 99 \\
\cline { 2 - 5 } & Rural & 94 & 84 & 180 \\
\hline \multirow{7}{*}{ Age } & Urban & 61 & 42 & 103 \\
\cline { 2 - 5 } & $15-24$ & 3 & 0 & 3 \\
\cline { 2 - 5 } & $25-34$ & 6 & 2 & 8 \\
\cline { 2 - 5 } & $35-44$ & 14 & 23 & 37 \\
\cline { 2 - 5 } & $45-54$ & 31 & 33 & 64 \\
\cline { 2 - 5 } & $55-64$ & 34 & 42 & 76 \\
\cline { 2 - 5 } & $>65$ & 69 & 26 & 95 \\
\hline
\end{tabular}

\section{Clinical Presentations and Identified Risk Factors}

The most common clinical presentation was hemiparesis with $190(67.1 \%)$ followed by aphasia with $43(15.2 \%)$ and $22(7.8 \%)$ of patients initially presented within 185 (61\%) patients and $56(18.4 \%)$ patients presented with loss of consciousness. And $24(8.5 \%)$ patients presented with a combination of clinical features (hemiparesis + aphasia + facial palsy), and only $2(0.7 \%)$ of patients presented with isolated facial palsy (Table 2). The most common risk factor identified was hypertension with 133(47\%) patients followed by cardiac conditions with $16(5.7 \%)$ patients having an arrhythmia, $8(2.8 \%)$ having ischemic heart disease, and valvular heart disease and cardiomyopathy with $3(1.1 \%)$ patients each. $64(22.6 \%)$ patients had more than one risk factor for stroke, while in $47(16.6 \%)$ patients no risk factors were identified (Table 3 ).

Table 2: Clinical presentation of stroke patients who underwent CT scanning at Jimma university medical center from December 11, 2016, up to October 8, 2019.

\begin{tabular}{|c|c|c|c|}
\hline $\begin{array}{c}\text { Clinical } \\
\text { presentation }\end{array}$ & $\begin{array}{c}\text { Infarction } \\
\mathbf{n}(\%)\end{array}$ & $\begin{array}{c}\text { Hemorrhage } \\
\mathbf{n}(\%)\end{array}$ & Total \\
\hline Comma & $7(31.8 \%)$ & $15(68.2 \%)$ & $22(7.8 \%)$ \\
\hline Aphasia & $22(51.2 \%)$ & $21(48.8 \%)$ & $43(15.24 \%)$ \\
\hline Hemiparesis & $108(56.8 \%)$ & $82(43.2 \%)$ & $190(67.37 \%)$ \\
\hline Quadriplegia & $1(100 \%)$ & 0 & $1(0.354 \%)$ \\
\hline Headache & 0 & $1(100 \%)$ & $1(0.354 \%)$ \\
\hline Facial Palsy & $1(50 \%)$ & $1(50 \%)$ & $2(0.7 \%)$ \\
\hline
\end{tabular}

\begin{tabular}{|c|c|c|c|}
\hline $\begin{array}{c}\text { Combined } \\
\text { symptoms }\end{array}$ & $18(75 \%)$ & $6(25 \%)$ & $24(8.5 \%)$ \\
\hline Total & $156(55.3 \%)$ & $126(44.7 \%)$ & $282(100 \%)$ \\
\hline
\end{tabular}

Table 3: Identified risk factors in stroke patients in Jimma university Medical Center from December 11, 2016, up to October 8, 2019.

\begin{tabular}{|c|c|c|c|}
\hline Risk Factor & $\begin{array}{c}\text { Infarction } \\
\text { n (\%) }\end{array}$ & $\begin{array}{c}\text { Hemorrhage } \\
\text { n (\%) }\end{array}$ & $\begin{array}{l}\text { Total } \\
\text { n (\%) }\end{array}$ \\
\hline Hypertension & $52(39.1 \%)$ & $81(60.9 \%)$ & $133(47.16)$ \\
\hline Diabetes Mellites & $4(100 \%)$ & 0 & $4(1.41 \%)$ \\
\hline Dyslipidemia & $2(100 \%)$ & 0 & $2(0.7)$ \\
\hline Smoking & $1(100 \%)$ & 0 & $1(0.35 \%)$ \\
\hline \multicolumn{4}{|l|}{ Cardiac Disease } \\
\hline $\begin{array}{l}\text { Valvular heart } \\
\text { disease }\end{array}$ & $2(66.7)$ & $1(33.3)$ & $3(1.06 \%)$ \\
\hline $\begin{array}{c}\text { Ischemic } \\
\text { heart disease }\end{array}$ & $8(100 \%)$ & 0 & $8(2.83 \%)$ \\
\hline Cardiomyopathy & $2(66.7 \%)$ & $1(33.3 \%)$ & $3(1.06 \%)$ \\
\hline Arrhythmia & $11(68.8 \%)$ & $5(31.3 \%)$ & $16(5.67 \%)$ \\
\hline \multicolumn{4}{|l|}{$\begin{array}{c}\text { Combined Risk } \\
\text { Factors }\end{array}$} \\
\hline $\mathrm{HTN}+\mathrm{DM}$ & $9(75 \%)$ & $3(25 \%)$ & $12(4.25 \%)$ \\
\hline $\begin{array}{c}\text { HTN + } \\
\text { Dyslipidemia }\end{array}$ & $7(100 \%)$ & 0 & $7(2.48 \%)$ \\
\hline $\begin{array}{c}\text { HTN + } \\
\text { cardiomyopathy }\end{array}$ & $7(30.4 \%)$ & $16(69.6 \%)$ & $23(8.156 \%)$ \\
\hline HTN + IHD & $7(43.8 \%)$ & $9(69.6 \%)$ & $16(5.67 \%)$ \\
\hline $\begin{array}{l}\text { Arrhythmia } \\
+ \text { IHD }\end{array}$ & $5(100 \%)$ & 0 & $5(1.77 \%)$ \\
\hline $\begin{array}{l}\text { Valvular HD } \\
+ \text { IHD }\end{array}$ & $1(100 \%)$ & 0 & $1(0.35 \%)$ \\
\hline Coagulopathy & $1(50 \%)$ & $1(50 \%)$ & $2(0.7)$ \\
\hline $\begin{array}{l}\text { No identified } \\
\text { risk factors }\end{array}$ & $36(78.2 \%)$ & $10(21.8 \%)$ & $46(16.31 \%)$ \\
\hline Total & $155(54.9 \%)$ & $127(45.1 \%)$ & $282(100 \%)$ \\
\hline
\end{tabular}

\section{CT Scan Patterns of Stroke}

The most common pattern of stroke documented in the CT findings was hemorrhagic stroke with $126(44.5 \%)$ followed by ischemic stroke $122(43.1 \%)$. And in 34(12\%) patients the CT scan findings didn't show any abnormalities. And in a $1(0.4 \%)$ person had a hemorrhagic transformation of an ischemic stroke (Figure 1). The commonest location for ischemic stroke was the cerebra hemispheres in $84(68.9 \%)$ patients followed by the basal ganglia $26(21.3 \%)$ patients and $3(2.5 \%)$ patients had cerebellar infarcts and $2(1.6 \%)$ patients had a brainstem infarct. 7(5.7\%) patients had an infarction of multiple sites (Figure 2). Hemorrhagic stroke was commonly seen in the basal ganglia with $61(48.0 \%)$ of patients, followed by the thalamus 35(27.6\%), 5(3.9\%) patients each had hemorrhages localized to the internal capsule and brainstem. 
$3(2.4 \%)$ of patients had a stroke on multiple sites (Figure 3$)$. Among the patients with Hemorrhagic stroke in $76(59.8 \%)$ of them, the bleeding was localized to the brain parenchyma and in 48(37.8\%) of the patients the bleeding had an intraventricular extension and 3 patients had an extension to the subarachnoid space. In the lobar distribution of stroke, the commonest site involved was the subcortical grey matter with $129(52 \%)$, the frontal lobe is involved in $33(13.3 \%)$ followed by parietal lobe in $23(8.3 \%)$ and $39(13.8 \%)$ of the patients had multi lobar involvement (Table 4).

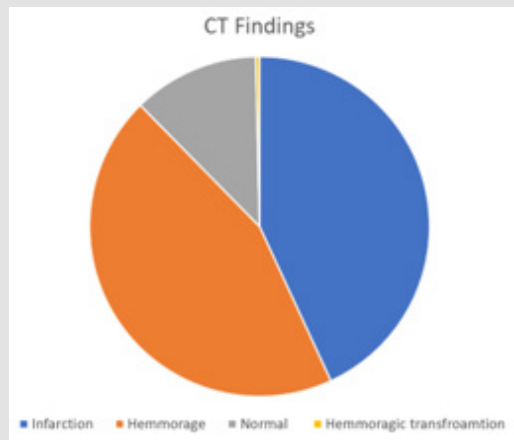

Figure 1: CT scan pattern of stroke patients who underwent CT scan at Jimma university Medical center from December 11, 2016, up to October 8, 2019.

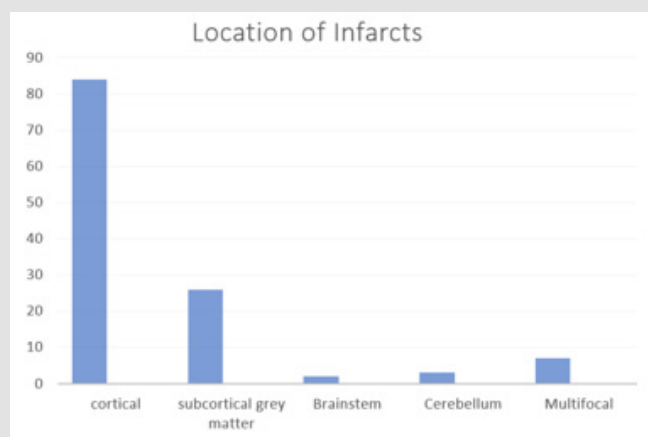

Figure 2: Anatomic location of ischemia in stroke patients who underwent CT scanning at Jimma University Medical center from December 11, 2016, up to October 8, 2019.

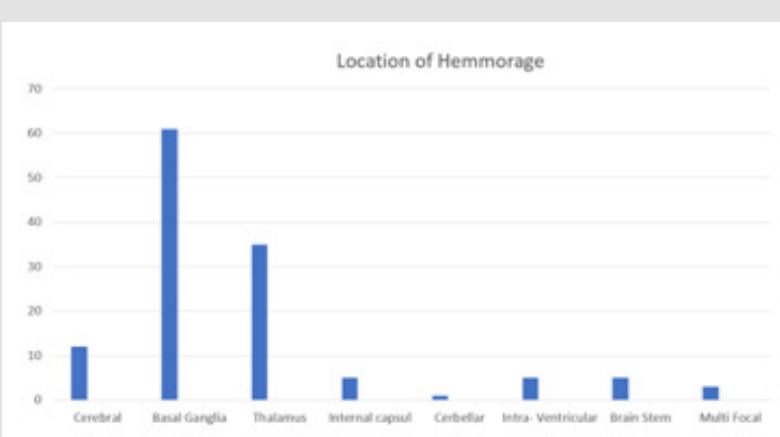

Figure 2: Anatomic location of hemorrhage in stroke patient who underwent CT scanning at Jimma University Medical Center. from December 11, 2016, up to October 8, 2019. 
Table 4: lobar distribution of stroke in patients who underwent CT scanning for stroke at Jimma University Medical Center. from December 11, 2016, up to October 8, 2019.

\begin{tabular}{|c|c|c|c|}
\hline Lobar site & $\begin{array}{c}\text { Infarction } \\
\mathbf{n}(\%)\end{array}$ & $\begin{array}{c}\text { Hemorrhage } \\
\mathbf{n}(\mathbf{\%})\end{array}$ & $\begin{array}{c}\text { Total } \\
\mathbf{n}(\mathbf{\%})\end{array}$ \\
\hline Parietal lobe & $17(73.9 \%)$ & $6(26.1 \%)$ & $23(9.3 \%)$ \\
\hline Frontal Lobe & $29(87.9 \%)$ & $4(12.1 \%)$ & $33(13.3 \%)$ \\
\hline Occipital lobe & $1(33.3 \%)$ & $2(67.7 \%)$ & $3(1.2 \%)$ \\
\hline Temporal Lobe & $7(100 \%)$ & 0 & $7(2.8 \%)$ \\
\hline $\begin{array}{c}\text { Sub cortical } \\
\text { grey matter }\end{array}$ & $27(20.9 \%)$ & $102(79.1 \%)$ & $129(52.0 \%)$ \\
\hline Cerebellum & $3(60 \%)$ & $2(40 \%)$ & $5(2 \%)$ \\
\hline Brainstem & $2(28.6 \%)$ & $5(71.4 \%)$ & $7(2.8 \%)$ \\
\hline Multi- lobar, & $36(92.3 \%)$ & $3(7.7 \%)$ & $39(15.7 \%)$ \\
\hline $\begin{array}{c}\text { Non } \\
\text { parenchymal }\end{array}$ & 0 & $2(100 \%)$ & $2(0.8 \%)$ \\
\hline Total & 122 & 126 & $248(100 \%)$ \\
\hline
\end{tabular}

\section{Discussion}

Head CT remains an important investigative modality for patients with various neurological disorders. Among the commonest indication for CT scan evaluation is stroke. In this study, we performed CT scan imagining patterns among patients who underwent CT scans for clinical suspicion of Stroke. In the study there was a male predominance among stroke patient's males making up $65 \%$ of the cases, this is in line with the researchers conducted in other parts of the country like Bahir dar, Hawassa and Addis Ababa [8-10] as well as other researches are done in subSaharan African countries such as Nigeria, Cameron [11,12] and western countries such as the USA and Europe [13-15]. The mean age of stroke in the study was ( $57 \pm 14$ years) with patients and the age group of above 65 was the most commonly affected. This was in line with studies conducted in other parts the country and other developing countries, which had mean ages ranging from 50-62 [14-16]. In the study, both ischemic, as well as hemorrhagic stroke, were more common in patients who came from rural parts of the study area compared to people living in the urban region. These finding were also replicated in other studies done in the country $[2,4,14]$ but differ from other studies that are done in other African countries as well as those done abroad [7,15-16] and possible reason for these discrepancies are believed to be Regional sociocultural difference as well as differences in the access to health care services.

The most common type of stroke In the study was hemorrhagic stroke which is a comparable to similar studies conducted in the country $[2,17,18]$ as well other countries such as Tanzania, Rwanda, Ghana [16-18] while some studies were done in Kenya, Zambia, Senegal, Nigeria showed higher incidences of ischemic stroke this can be due to differences in the Demographic and Risk factors as the studies in which ischemic stroke was more common had an older mean age and increased incidence of certain risk factors such as diabetes, Alcohol \& tobacco use as well as higher rates of HIV infections [19-22]. The most common Risk factors seen in stroke Patients were Hypertension which was seen in around $40 \%$ of patients with ischemic stroke and $60 \%$ of patients with Hemorrhagic stroke, this finding is reproduced in all studies conducted in the country as well as other African countries this may be because uncomplicated Hypertension is usually symptomless and patents may not be aware of their illness and even after diagnosis long term compliance will be an issues as patients might believe that they have been healed as soon as their symptoms disappear. The other established Risk factors of stroke such as Diabetes, smoking, Dyslipidemia were less common in this study than other studies. [3,15,20-22].

The commonest location for Hemorrhagic stroke was the basal ganglia, thalamus, which accounted for $75 \%$ of the cases, these locations are common sites for hemorrhage secondary to Hypertension due to the branching pattern of the lenticulostriate vessels which supply these areas which are susceptible to rupture in cases of elevated blood pressure which was noted in these patients. Other identified sites of hypertensive bleeds are the cerebellum, internal capsule, and brainstem which accounted for around $9 \%$ of the cases [24]. The comments locations of ischemic stroke were the cortical grey matter with $70 \%$ followed by the subcortical grey matter which accounted for around $20 \%$ of the cases while the rest of the cases were located in the brainstem and the cerebellum. This location is well described to be susceptible to infarcts due to the anatomy of the vessels [25].

\section{Limitations of the Study}

Not all patients clinically diagnosed to have stroke did not have CT scans for confirmations and further characterizations due to several reasons. The fact that the study was retrospective medical records were incomplete in most of the study subjects.

\section{Conclusion}

The study shows that stroke is a major public health concern and A prospective community-based study is required to define the true magnitude and socio-demographic characteristics of stroke and the associated factors in the general population. Strategies for screening and management of hypertension, structural heart disease, and atrial fibrillation should be given priority as these are the most prevalent risk factors identified. An emergency care setup capable of early patient evaluation with appropriate Neuroimaging and management of early stroke complications is crucial for prevention of early stroke-related mortality.

\section{Acknowledgment}

The authors would like to thank the data clerks in the Jimma university medical center for their assistance in the data collection process. 


\section{References}

1. Feigin VL, Norrving B, Mensah GA (2017) Global Burden of Stroke 120(3): 439-448

2. Fekadu G, Wakassa H, Tekle F (2019) Stroke Event Factors among Adult Patients Admitted to Stroke Unit of Jimma University Medical Center: Prospective Observational Study. Stroke Res Treat 2019.

3. Getachew Erkabu S, Agedie Y, Mihretu DD, Semere A, Alemu YM (2018) Ischemic and Hemorrhagic Stroke in Bahir Dar, Ethiopia: A Retrospective Hospital-Based Study. J Stroke Cerebrovasc Dis 27(6):1533-1538.

4. Deresse B, Shaweno D (2015) Epidemiology and in-hospital outcome of stroke in South Ethiopia. J Neurol Sci 355(1-2): 138-142.

5. Berkowitz AL, Westover MB, Bianchi MT (2014) Aspirin for acute stroke of unknown etiology in resource-limited settings_ a decision analysis. American Academy of Neurology 83(9): 787-793.

6. Getachew, Assefa (2010) Department of Radiology, FOM A. Ethiopian medical Journal. Ethiop Med J 48(2): 117-122.

7. Truelsen T, Begg S, Mathers C (2001) The global burden of cerebrovascular disease.

8. Kaur P, Verma SJ, Singh G, Bansal R, Paul BS, et al. (2017) Stroke profile and outcome between urban and rural regions of Northwest India: Data from Ludhiana population-based stroke registry. Eur Stroke J 2(4): 377 384.

9. Deresse B, Shaweno D (2015) Epidemiology and in-hospital outcome of stroke in South Ethiopia. Journal of the Neurological Sciences 355(1-2): 138-142.

10. Sultan M, Debebe F, Azazh A, Hassen GW (2017) Epidemiology of stroke patients in Tikur Anbessa Specialized Hospital: Emphasizing clinical characteristics of Hemorrhagic Stroke Patients. Ethiop J Heal Dev. 31(1): 13-17.

11. Lekoubou A, Nkoke C, Dudzie A, Pascal A (2016) Computed tomography scanning and stroke mortality in an urban medical unit in Cameroon. eNeurological Sci 2: 3-7.

12. Watila MM, Nyandaiti YW, Bwala SA, Ibrahim A (2011) Gender variation in risk factors and clinical presentation of acute stroke. Northeastern Nigeria 3: 38-43.

\section{ISSN: 2574-1241}

DOI: $10.26717 / B J S T R .2020 .29 .004835$

Abdi Dandena. Biomed J Sci \& Tech Res

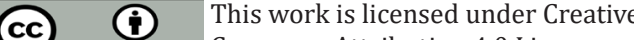

Commons Attribution 4.0 License

Submission Link: https://biomedres.us/submit-manuscript.php
13. Lori Mosca, Pamela Ouyang, Carl A Hubel, Harmony R Reynolds (2009) Go Red for Women A Systematic Review. 135(6): 1082-1090.

14. Petrea RE, Beiser AS, Seshadri S, Kelly hayes M, Kase CS (2009) Go Red for Women Gender Differences in Stroke Incidence and Poststroke Disability in the Framingham Heart Study 40(4): 1032-1037.

15. Differences S, Incidence S, Burden G, Study D (2016) DALYs : Results from the Global Burden of Disease Study 2013. 45(3): 203-214.

16. Atadzhanov M (2012) Stroke Characteristics and Outcomes of Adult Patients Admitted to the University Teaching Hospital, Lusaka, Zambia. Open Gen Intern Med J 5(1): 3-8.

17. Fekadu G, Chelkeba L, Melaku T, Tegene E (2018) Pathological Sub Types and Diagnostic Protocols of Stroke among Adult Patients Admitted to Jimma University Medical Center, South West Ethiopia. J Neurol Neurophysiol 9(4).

18. Gedefa B, Menna T, Berhe T, Abera H (2017) Assessment of Risk Factors and Treatment Outcome of Stroke Admissions at St. Paul's Teaching Hospital, Addis Ababa, Ethiopia. J Neurol Neurophysiol 8(3): 6-11.

19. Matuja W, Janabi M, Kazema R, Mashuke D (2004) Stroke Subtypes in Black Tanzanians: A Retrospective Study of Computerized Tomography Scan Diagnoses at Muhimbili National Hospital, Dar es. Trop Doct 34(3): 144-146.

20. Sagui E, M Baye PS, Dubecq C, Fall KB, Niang A, et al. (2005) Ischemic and hemorrhagic strokes in Dakar, Senegal: A hospital-based study. Stroke 36(9): 1844-1847.

21. Watila MM (2012) Risk factor profile among black stroke patients in Northeastern Nigeria. J Neurosci Behav Heal. 4(5): 50-58.

22. Ominde BS, Ogengo JA, Misiani MK, Kariuki BN (2019) Pattern of stroke in a rural Kenyan hospital. Malawi Med J 31(1): 50-55.

23. Nkusi AE, Muneza S, Nshuti S, Hakizimana D, Munyemana P, et al. (2017) Stroke Burden in Rwanda: A Multicenter Study of Stroke Management and Outcome. World Neurosurg 106: 462-429.

24. Anne G Osborn, Gary L (2018) Hedlund DA, Karen L. Salzman M. osbourn brain imaging,pathology and anatomy. In: osbourn brain imaging,pathology and anatomy. 2nd ed. Elsevier pp. 93-122.

25. Anne G Osborn, Gary L, Hedlund D, Karen L (2017) Salzman M. osbourn brain imaging, pathology, and anatomy. In Anne G Osborn, Gary L, Hedlund D, Karen L (Eds.), ( ${ }^{\text {nd }}$ edn.), Elsevier, USA, pp. 197-252.

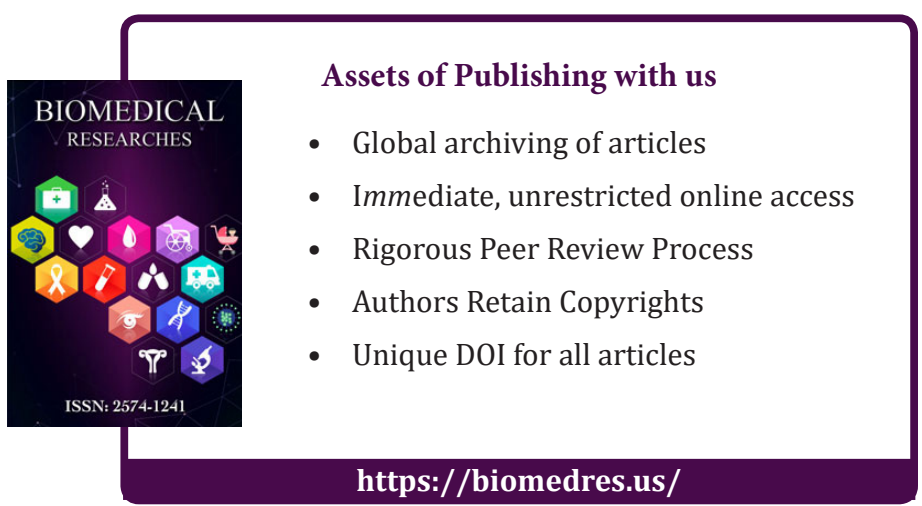

